\title{
Remodeling by fibroblasts alters the rate-dependent mechanical properties of collagen
}

\author{
Behzad Babaei $^{+a}$, Ali Davarian ${ }^{+c}$, Sheng-Lin Lee ${ }^{\mathrm{a}, \mathrm{b}}$, Kenneth M. Pryse ${ }^{\mathrm{c}}$, William B. McConnaughey ${ }^{\mathrm{c}}$, \\ Elliot L. Elson ${ }^{\mathrm{c}}$, Guy M. Genin ${ }^{\mathrm{a}, *}$ \\ ${ }^{a}$ Department of Mechanical Engineering \& Materials Science, Washington University in St. Louis, St. Louis, Missouri, USA \\ ${ }^{b}$ Department of Physics, National Taiwan University, Taipei, Taiwan \\ ${ }^{c}$ Department of Biochemistry \& Molecular Biophysics, Washington University School of Medicine, St. Louis, Missouri, USA \\ +contributed equally
}

\begin{abstract}
The ways that fibroblasts remodel their environment is central to wound healing, development of musculoskeletal tissues, and progression of pathologies such as fibrosis. However, the changes that fibroblasts make to the material around them and the mechanical consequences of these changes have proven difficult to quantify, especially in a realistic, viscoelastic three dimensional culture environments, leaving a critical need for quantitative data. Here, we observed the mechanisms and quantified the mechanical effects of fibroblast remodeling in engineered tissue constructs (ETCs) comprised of reconstituted rat tail (type I) collagen and human fibroblast cells. To study the effects of remodeling on tissue mechanics, stress-relaxation tests were performed on ETCs cultured for 24, 48, and 72 hours. ETCs were treated with deoxycholate and tested again to assess the ECM response. Viscoelastic relaxation spectra were obtained using the generalized Maxwell model. Cells exhibited viscoelastic damping at two finite time constants over which the ECM showed little damping, approximately $0.2 \mathrm{~s}$ and 10-30 s. Different finite time constants in the range of 1-7000 s were attributed to ECM relaxation. Cells remodeled the ECM to produce a relaxation time constant on the order of $7000 \mathrm{~s}$, and to merge relaxation finite time constants in the 0.5-2 s range into a single time content in the $1 \mathrm{~s}$ range. Results shed light on hierarchical deformation mechanisms in tissues, and on pathologies related to collagen relaxation such as diastolic dysfunction.
\end{abstract}

Keywords: Human dermal fibroblasts, Collagen, Remodeling, Viscoelasticity

\section{Introduction}

Interactions between living cells and their mechanical environments are central to a host of physiologic and pathologic events ranging from development to metastatis to wound healing. Fibroblasts remodel their extracellular neighborhood considerably when activated, stiffening and compressing their extracellular matrix (ECM) environment 1, 2, 3, 4, 5, 6, 7, 8, 9,. During remodeling, fibroblasts secrete ECM proteins, including collagens, proteoglycans, glycoproteins, and proteases, and cross-linking proteins and enzymes [1, 2, 3, 4, 10, Fibroblasts exert traction on the ECM and each other 9, 11, 12, 13, and secrete soluble factors that affect

\footnotetext{
*Corresponding author

Email address: genin@wustl.edu (Guy M. Genin)
} 
neighboring cells and tissues in a paracrine manner [14. This remodeling changes the tissue as a whole by establishing a network to link and organize individual cells [15, 16, 17, 18, 19, 20].

Although several studies have estimated the effects of this remodeling on ECM elasticity [5, 21, much less is known about the viscoelastic effects of ECM remodeling. Fibroblasts are known to affect viscoelastic tissue relaxation in pathologies such as congestive heart failure. However, these effects have not been quantified, and there is a pressing need for data on viscoelastic remodeling of tissues.

Additionally, the cells themselves change during remodeling. Cytoskeletal disposition is known to change in response to perturbations in mechanical loading [22, 23, 24]. During wound healing, cytoskeletal structure is regulated to develop force against the ECM to close the wound 25]. Cell transformation and tumorigenicity are associated with a decrease in cell viscosity and elasticity [26]. Although well established techniques exist for estimating cell elasticity within engineered tissues [27, 5], protocols are still needed to acquire information about cell viscoelasticity.

Engineered tissue constructs (ETCs) comprised of reconstituted rat tail (type I) collagen and human dermal fibroblast cells serve as in vitro models of this remodeling, and provide simplified systems in which to assess how remodeling affects the mechanics of cells and ECM [28, 29]. These systems have been applied to study both linear and nonlinear elasticity of cells and ECM, but variations of time-dependent tissue mechanics by ECM remodeling has not been well characterized quantitatively.

The goal of this study was to establish the ways that fibroblast cells modulate their ECM viscoelastically and contribute to ETC-level viscoelasticity over the course of ETC remodeling. We studied these effects by performing viscoelastic relaxation tests on ETCs at three different timepoints. Following techniques that are standard for evaluation of ECM elasticity, ECM viscoelasticity was evaluated by treating ETCs with deoxycholate, a mild detergent which dissolves cell membranes and disperses cytoplasmic structures such as the cytoskeleton. Tests were interpreted using a discrete spectral generalized Maxwell approach [30, which yields both elastic moduli and viscoelastic relaxation finite time constants. Results showed that cells actively adapted the ECM, and that cells relax at multiple timescales, including one that is fast compared to those of the ECM.

\section{Materials and methods}

\subsection{Engineered tissue construct (ETC) preparation}

ETCs were synthesized using procedures described in detail elsewhere [25]. Briefly, human dermal fibroblasts (Lonza, Allendale, NJ, USA) were cultured in Dulbecco's modified Eagle's medium (DMEM, Gibco) at $37^{\circ} \mathrm{C}$ and $5 \% \mathrm{CO}_{2}$. The media were changed every 3-4 days and the cells were split when cell confluency reached $>80 \%$ of the dish surface. The cells were used for culturing ETCs at the 7th-10th passage. 0.5 million cells were mixed with $1 \mathrm{ml}$ of a solution consisting of DMEM and $0.5 \mathrm{mg} / \mathrm{ml}$ type I rat tail collagen (harvested in our laboratory). The $\mathrm{pH}$ of this mixture was brought to neutrality using $0.2 \mathrm{M} \mathrm{NaOH}$. $0.5 \mathrm{ml}$ of this mixture was poured into hollow, cylindrical Teflon molds; the molds contained a central rod to create an annular well with outer and inner diameters of $14.9 \mathrm{~mm}$ and $9.5 \mathrm{~mm}$, respectively. The final mixture was incubated at $37^{\circ} \mathrm{C}$ 
with $5 \% \mathrm{CO}_{2}$ for 30 minutes to allow the collagen to polymerize. Then, the molds were filled with DMEM supplemented with $5 \%$ fetal bovine serum (FBS) and were kept in an incubator for 24, 48 or 72 hours to allow the cells to remodel the collagen. Three specimens were tested at each of the three remodeling times, a total of nine specimens.

\subsection{Stress-relaxation testing apparatus and protocol}

Stress-relaxation tests were performed on the ring-shaped ETCs. ETCs were mounted within glass organ baths filled with HEPES-buffered DMEM ( $\mathrm{pH} 7.4$ ) and $5 \% \mathrm{FBS}$, and kept at $37^{\circ} \mathrm{C}$, conditions standard for culturing engineered tissues [31. One end was attached to an actuator connected to a stepper motor, and the other to a force transducer, as described elsewhere [25]. Tissues were allowed one hour to accommodate to the new media before the stress-relaxation test. The protocol started with 10 minutes of force monitoring to establish a baseline. This was followed by tissue preconditioning consisting of 5 sequential cycles of a $20 \%$ axial stretch, followed by a 30 minute recovery interval. A preconditioning protocol is standard in testing of collagenous tissues [32. Using a strain rate analogous to that of the subsequent characterization experiments and a strain magnitude twice that used in the characterization experiments yields repeatable results in the testing of ETCs [27, 33].

In the characterization experiments, ETC rings were stretched $10 \%$ at $20 \% / \mathrm{s}$ then held isometrically for $3600 \mathrm{~s}$ while force was recorded at $50 \mathrm{~Hz}$. Nominal stress data were inferred from force data by dividing the force by the cross-sectional area measured for each specimen at the conclusion of the test, as described below. Note that, despite the preconditioning, the specimens likely experienced some permanent deformation over the course of the loading; by considering a transversely isotropic specimen with a Poisson ratio of 0.5 locked into its deformed configuration, the difference between the actual first Piola Kirchoff stress and that we report can be estimated to be less than $10 \%$. The strain amplitude of $10 \%$ strain was chosen because it represents the upper end of the linear range for a tendon [34]. Achieving this over 0.5 seconds is representative of strains in response to a brisk walking cadence and to stretching by the cardiovascular system. The stretch rate and prolonged monitoring were furthermore suitable for characterizing the temporal range of physiological responses $[30,35$.

\subsection{Deoxycholate treatment}

The specimens were returned to their baseline configurations and allowed to recover for 30 minutes to prepare for testing the contribution of the remodeled ECM to viscoelastic behavior of the ring constructs. For

this purpose, DMEM+HEPES was replaced with $0.05 \% \mathrm{w} / \mathrm{v}$ deoxycholate in PBS ( $\mathrm{pH} 7.4$ ), and allowed to incubate for 60 minutes. The stretch-and-hold protocol was then repeated. Deoxycholate was chosen over inhibitors such as cytochalasin D and latrunculin because it enables lysis of cells without altering the mechanics of the protein structure in the remaining porous ECM [36, 27.

\subsection{Measurement of ETC dimensions}

After the end of each experiment, specimens were mounted on spacers and stretched to their reference length, then fixed in $4 \%$ formaldehyde for 20 minutes at room temperature. Afterwards, specimens were cut into two 
equal pieces and placed within four-well plates filled with PBS. The width and thickness of each tissue were measured using Confocal microscopy (LSM 510, Zeiss). The thickness was measured near the upper and lower borders as well as in the middle of the tissue. The cross sectional area of the tissue was calculated as the mean of the three measurements. All measurements were conducted by the same person.

\subsection{DNA quantification}

We synthesized an additional 9 specimens (three each at 24, 48, and 72 hours of incubation) to estimate the final cell concentration in ETCs using a total DNA quantification assay. Right after the measurement of tissue dimensions, the constructs were centrifuged with $2 \mathrm{ml}$ PBS in capped tubes. PBS was removed and, after 1 $\mathrm{ml}$ of lysis buffer was added, the tubes were sonicated. $30 \mu \mathrm{l}$ of this sample was mixed with $3 \mathrm{ml}$ of Hoechst solution (30 nM of Hoechst 33258 per ml of PBS) (Sigma, St. Louis, MO). The fluorescence of this mixture was read at excitation-emission of $346 \mathrm{~nm}-460 \mathrm{~nm}$ max, respectively. A known number of human dermal fibroblast cells was used as a calibration to estimate the number of cells in the mixtures.

\subsection{Analysis of stress-relaxation data}

The generalized Maxwell model was used to interpret the relaxation behavior of the specimens tested. We used a discrete spectral implementation described elsewhere [30, based on a large number $(n=1000)$ of exponential terms. In the discrete spectral approach, the relaxation times, $\tau_{i}$, were logarithmically distributed equidistantly over a range broader than probable range of time constants of a material. The best fit elastic moduli $E_{i}$ for each pre-selected $\tau_{i}$ were estimated by minimizing the mean squared error between the experimental data and the fitting arising from the estimated viscoelastic spectrum. We note that MSE is superior to $R^{2}$ for identifying viscoelastic relaxation spectra from relaxation spectra because even a mediocre fit can yield $R^{2} \approx 1$ [30. The spectrum arising by plotting $E_{i}$ versus the pre-selected $\tau_{i}$ yielded an unbiased relaxation spectrum that enabled simple, graphical material identification.

\subsection{Staining and imaging}

The actin cytoskeletons of the fixed tissues were stained with rhodamine phalloidin (Sigma, St. Louis, MO) and imaged using confocal microscopy. Images were obtained with a Zeiss 510 confocal microscope using a 40x, 1.2 NA, water objective. In backscattering reflectance mode confocal microscopy, collagen fibers of ETCs can be observed directly without staining and with good axial and lateral resolution.

\subsection{Statistical methods}

All experiments were repeated in at least triplicate. Mean and standard deviation were reported. For estimates of the number of cells, cross-sectional area, and cell concentration in an ETC, mean and standard deviation were reported. Error bars were drawn to represent standard deviation. A key factor was the evolution of morphology over time (specifically, the 24, 48 and 72 hours time points). Students $T$ - test was used to compare data at different time points, with $p<0.05$ taken as the threshold for statistical significance. To show their statistical variance relaxation data and spectra, from all replicate tests were included in the supplemental document. 


\section{Results}

\subsection{Remodeling of ETCs}

Over three days of remodeling, cells proliferated and compressed the ETCs (Fig. 1a), with the initial crosssection area (thickness $\times$ width) decreasing from $13.8 \times 10^{-6} \mathrm{~m}^{2}$ (initial solution poured into the mold) to $1.01 \times 10^{-6} \mathrm{~m}^{2}$ during the first 24 hours, and to $0.51 \times 10^{-6} \mathrm{~m}^{2}$ after 72 hours. The starting population of $250 \times 10^{3}$ cells (in $0.5 \mathrm{ml}$ of solution) was sustained for 24 hours, and decreased to about $190 \times 10^{3}$ after 72 hours (Fig. 1b). The initial cell concentration for all ETCs was 0.5 million cells/ml. Over 24, 48 and 72 hours of incubation, cell concentration rose to approximately 8,10 and 12 million cells/ml, respectively (Fig. 1c).

\subsection{Mechanical responses}

In response to the ramped stretch, the stress needed to maintain an ETC at its length increased to a peak value. As the ETC was held isometrically, this stress dropped over time as a result of viscoelastic relaxation for both the control (Figs. 2a, 2c and 2e) and deoxycholate-treated (Figs. 2b, 2d and 2f) ETCs.

These stress-relaxation curves changed as the course of remodeling progressed, and were analyzed to quantify the effects of remodeling. The peak stresses attained immediately following cessation of the ramp tended to increase as the cells continued remodeling the ETCs over time for both the control and deoxycholate-treated ETCs. From the 24 to the 72 hour time points, peak stress doubled for the control ETCs (Fig. 3a) and more than doubled for the deoxycholate-treated ETCs (Fig. 3b); these trends were significant statistically $(p<0.001)$. Additionally, the peak force in the ETCs rose significantly between 24 and 48 hours, indicating that the stiffening extended beyond that associated with syneresis (Fig. S7). Treatment with dexoxycholate more than halved the peak stress in each case. The minimum stress in the deoxycholate-treated ETCs rose from the 24- to the 48-hour time point $(p<0.05$, Fig. $3 \mathrm{~b})$.

The stress relaxation was analyzed using a spectral approach that, through integration with tests involving deoxycholate, quantified the rheological responses of the cells and ECM over a range of loading time constants. The analyses demonstrated that the relaxation mechanisms of ETCs cannot be described by one simple exponential term (Fig. 4).

The analysis showed subtle but significant transitions in some of the viscoelastic relaxation time constants over the course of ECM remodeling, with a slower finite time constant ( 7000 s) emerging between 24 and 48 hours of remodeling, and with some faster time constants $(0.5-2 \mathrm{~s})$ merging into a single time constant between 48 and 72 hours of remodeling. As discussed below, these changes were retained following deoxycholate treatment, indicating that the changes occurred in the ECM rather than in the cells. In the deoxycholate treated ETCs, with cells eliminated, the $0.2 \mathrm{~s}$ time constant disappeared at all time points. At 24 hours, the $\sim 8 \mathrm{~s}$ time constant disappeared with deoxycholate treatment, and at 48 and 72 hours, the $30 \mathrm{~s}$ time constant disappeared (Figs. 4b, 4d and 4f). The elastic moduli decreased for the deoxycholate treated ETCs with respect to control samples (Figs. 4a, 4c and 4e) at finite time constants faster than $100 \mathrm{~s}$. Variance amongst the relaxation spectra was greatest for the 48-hour time point. 


\subsubsection{Imaging of ETCs}

Imaging of 24-hour-old-old ETCs showed a disordered collagen fibers (representative image, Fig. 5a). For 48-hour-old ETCs, a transitional state could be observed in which collagen fibers were more organized and began to exhibit a preferred orientation (representative image, Fig. 5b). Finally, a very compact pattern of collagen fibers appeared in 72-hour-old ETCs (representative image, Fig. 5c). This compact pattern could be found at a multitude of locations throughout the ETCs, not only close to the edges. Cells in ETCs could establish a network that linked and organized cells not only in the direction of circumferential restraint but also perpendicular to it (Fig. 6). The ECM contained several clusters of adjacent cells forming ring-like structures (e.g., Fig. 6).

\section{Discussion}

\subsection{Cells remodeled the ECM locally}

Many consequences of the interactions between cells and ECM were evident by observing the ETCs. Reflectance mode confocal microscopy, in which collagen fibers of ETCs can be observed directly without staining and with good axial and lateral resolution, showed that collagen fibers remodeled over time into a network showing elements of structural organization (Fig. 5). The latter typically aligned with the direction of circumferential constraint in the ring-shaped ETCs, and also connected cells or groups of cells (Fig. 6). Cells reduced ETC cross-sectional area as they collectively remodeled the ECM (Fig. 1).

Our images (Fig. 5 and Fig. 6) and data (Fig. S7, supplementary document) were consistent with previous experimental results [37, 15, 16] showing that remodeling involves more than simple syneresis. Remodeling mechanisms are believed to include increasing cross-linking of the collagen network, which helps collagen retain a compressed state and increases collagen fibril stiffness [38, 39]. Additionally, contractility [15, 16], enzymatic activity [40], and matrix synthesis [17] play roles.

The structural aspects of remodeling are central to the mechanics of ETCs [13, 31], and are particularly important for promising new therapies to improve cardiac function after myocardial infarction through guiding scar development [41]. They are also key to understanding how myofibroblasts invade an infarct region [42, 43. Additionally, these factors are central to healing of tendons, ligaments, and their bony attachments [44, 45, 46, 47, 48, 49, 50, 35. In all of these, percolation phenomena involving formation of a continuous structural network are important, and variance is typically highest in conditions close to percolation [4]. Indeed, in our study, the variance in relaxation spectra was highest in samples at the 48-hour time point, when images showed the beginnings of interconnection amongst remodeled regions of ECM. Although visualizing and quantifying the underlying mesoscale effects are open challenges [51, 52], an understanding of how viscoelasticity is mediated by such changes will be an important future component of such studies.

\subsection{ETC remodeling occurred over specific ranges of relaxation time constants}

A remarkable feature of the remodeling process was that the majority of the ETC relaxation time constants were not altered significantly (Fig. 4). Many others have quantified tremendous stiffening of ECM by cells 
[53, 54, 55] and substantial effects on the cells themselves [56], which appear to become more compliant with ECM stiffening in 3D [37] and more compliant in 2D [57]. Stiffening is typically small in tissue constructs that begin with cell concentrations below those in our study [58, 5]. However, measurable contributions of cells to ETC mechanics are evident even at cell concentrations far below those used in the current study [59]. A number of recent studies have shown that, when cell density is sufficiently high, cells can adapt the fibrous structure of the ECM to form connections and structures like those shown in Figs 5 and 6 [60, 16, 61, 62, 63, 15].

In the work reported here, remodeling of ETCs by fibroblasts showed a major effect on peak stresses in stress-relaxation tests (Fig. 2 and Fig. 3). In this light, the relative lack of viscoelastic effects comes as a surprise. The only exceptions were was that between 24 and 48 hours, a relatively long finite time constant emerged in both the ETCs and the ECM, and that between 48 and 72 hours of remodeling, two time constants 0.5 and $2 \mathrm{~s}$ merged into a single, intermediate time constant with a stronger amplitude. Because relaxation spectra are correlated to discrete structure of collagenous tissues [64, 65, 66, the merging of the two peaks indicates a decrease in the structural heterogeneity of the tissue during the remodeling process. These time constants are near those that others have been attributed to intra-fibril relaxation $(\sim 4-7 \mathrm{~s})$ [66, 65, 67]. One possible source of this merging of time constants is syneresis of inter-molecular water [68, 69]. Time constants in the 1s range are of particular interest for the cardiovascular system because this is associated with frequency of the heart. In fibrotic cardiomyopathy, a disease characterized by remodeling of heart tissue by activated cardiac myofibroblasts, a central pathology involves retarded diastolic filling [70, 71, possibly due in part to viscoelastic remodeling. Although the fibroblasts within the heart are believed to differ in subtle ways from those in the skin, viscoelastic remodeling in this frequency range warrants further study.

\subsection{Specific time constants can be attributed to cells, ECM, and components of the ECM}

Responses of the tissue constructs to mechanical stretching were quantified using a spectral approach that, through integration with tests involving specific inhibitors, quantified the rheological responses of the cells and extracellular matrix (ECM) over a range of loading time constants. Through these tests, some responses of cells and remodeled ECM could be dissected. We note that the analysis techniques are robust against data that have not reached a complete steady state [30]. A time constant estimated by the discrete spectral approach can be trusted if it is infinite or if it is less than twice the duration of the viscoelastic relaxation data: error was found to be on the order of $7 \%$ for a time constant that is twice the duration of the viscoelastic relaxation data 30. In Fig. 4, the slowest finite time constant was about $7000 \mathrm{~s}$, which is within this trusted range.

The decrease in the minimum stress of the deoxycholate-treated with respect to non-treated (control) ETCs shows that at least a part of the time-independent (elastic) behavior of tissues, which corresponds to the single spring in the generalized Maxwell model, is due to elastic contributions of the cells. Other studies confirm that the cells have elastic (time-independent) properties [72, 73].

Because deoxycholate treatment removed cells from ETCs, comparison of control and deoxycholate-treated ETCs enabled attribution of specific time constants to cell responses and to effects of ECM remodeling (Fig. 4). Six peaks in the relaxation spectra of 24 and 72-hour-old ETCs demonstrate six relaxation mechanisms, while 
for the 48-hour-old ETCs this number increased to seven. Two of the spectral peaks disappeared following treatment with deoxycholate (those at $0.2 \mathrm{~s}$ and $30 \mathrm{~s}$ for 48 hour and older specimens; $0.2 \mathrm{~s}$ and $8 \mathrm{~s}$ for 24 -hourold specimens) indicating that these are attributable to cells or cell-ECM interactions. Although cells might be expected to exhibit different relaxation behaviors under different environmental conditions, our results for the time constants of cells are within the range reported in other studies [72, 73, 74]. Wong et al. [75] reported that the major viscoelastic components of the cell cytoskeleton are responsible for vital mechanical functions, and found a slowest time constant for a cell of $0.28 \mathrm{~s}$, a number within the range of our findings. Nekouzadeh et al. [12] and Trepat et al. [76] found that very fast relaxation was associated with cytoskeletal fluidization; although they did not quantify the relaxation spectrum, we note that this is one possible explanation for the fastest time constant we observed. We note as well that the elastic moduli decreased for deoxycholate-treated ETCs for finite time constants below $100 \mathrm{~s}$ (Fig. 4), possibly due to loss of fibroblast contractility and contributions of voids in the ECM left by the lysis of cells.

The remaining four time constants (five after 48 hours) were all associated at least in part with the ECM. These time constants include several within the range of those found by others. Pryse et al. [77] found three plus an infinite time constant (approximately 5, 40, and 600s); Xu et al. [67, who estimated a regularized, continuous spectrum, found dominant time constants between 0.3-1 s, 3-90 s and $>200 \mathrm{~s}$ for collagen matrices. We note that ETCs exhibited some faster relaxation time constants than did collagen matrices, likely due to the action of cells.

Much work in the literature has focused on identifying the hierarchical structural origins of the elastic (timeindependent) and viscous (time-dependent) behaviors in collagenous tissues [78, 79, including work on effects of microstructural changes on the microscopic viscoelastic properties of collagen at different hierarchical levels [80, 68. The idea is that by analyzing the stress-relaxation data, and by assuming that different time constants correspond to specific hierarchical structures, one can gain insight into hierarchical contributions and distinguish different materials $81,82,83$; the elastic modulus at each time constant of the relaxation spectrum reflects the contribution of that time constant to ETC relaxation. Potential sources of viscous relaxation exist across collagen's hierarchical organization [68, 84]: triple-helix collagen molecules; cross-linked fibrils a few hundred $n m$ in diameter assembled from these molecules in a roughly triclinic lattice, and infiltrated by water and non-collagenous proteins; and cross-linked fibers assembled from these fibrils.

The work of Gupta et al. 65] and Shen et al. 85. identify the 7-10 and 100-110 s time constants as being associated with intra-fibril relaxation, and 2 and $33 \mathrm{~s}$ time constants as being associated with inter-fiber relaxation. Gupta et al. 65] notes that no intra-fiber relaxation was evident in their experiments. Relaxation time constants for intra-fiber interactions have not yet been characterized in any study of which we are aware. The $7000 \mathrm{~s}$ time constant we observed might be associated with this, or might be a feature of the larger structures within the tissue construct. The relaxation time constants of the tropocollagen molecules are on the order of microseconds 68 and appear to be masked at the level of tissue constructs.

An additional factor is water flow. At the molecular level, tropocollagen molecules bond covalently [68] and are surrounded by a hydration layer [86]. At the next hierarchical level, water plays a structural role, possibly 
maintaining spacing between collagen fibrils, while dehydration causes the tighter packing of fibrils and enhances mechanical rigidity by increasing intra-molecular hydrogen bonds [87, 88, 89]. Gautieri et al. [90, found that the dominant fibril-level deformation mechanism shifted from molecular sliding to molecular stretching with dehydration, with the latter exhibit higher stiffness.

Debate exists in the literature about how cross-linking affects stress-relaxation. Xu et al. 67] concluded that the viscoelastic response of a collagen gel depends upon cross-linking, while Feng et al. [91, comparing viscosity of artificial and native tissues, concluded that it does not. From the observations of remodeling dependent viscoelastic responses in this article, which includes effects of cross-linking, one can speculate that both groups are correct. The 100-110 s intra-fibril time constant persists throughout remodeling, while the 7-10 s time constant associated with intra-fibril relaxation seems coupled with cell responses in ETCs tested at 24 hours.

\subsection{Caveats}

A limitation of the current work is that the data acquired are strictly uniaxial. The off-axis contributions of cells to tissue viscoelasticity cannot be quantified. However, previous data do show that under the conditions of these experiments, the additive decomposition of the contributions of cells and ECM is a reasonable approximation [7, 6]. Moreover, for elongated cells appearing in these tissue constructs, the contributors of the transverse behavior of cells to the mechanics of the tissue construct is on the order of only a few percent $[92$.

A question that is raised in the study and elastic analysis of ETC mechanics is whether the mechanics of the porous ECM arising from deoxycholate treatment is representative of the true ECM mechanics. Although this is issue is largely resolved in the elastic analysis of tissue constructs [27, the question bears scrutiny in our viscoelastic analyses. Two questions arise. First, does deformation of pores in which cells resided an important (and irrelevant) deformation mechanism? If this were the case, then a new time constant or set of time constants associated with such deformation would be expected to appear in the relaxation spectrum. However, no such time constants appeared, and time constants associated with cells or cell/ECM interactions disappeared. Second, although deoxycholate does not change the short-term or long-term elastic response of the ECM [5], does it change the viscoelastic response? Again, no substantial shifting of time constants or appearance of new time constants was observed in the ECM relaxation spectra. Although the possibility exists that some of the time constants attributed to cells disappeared because of the action of deoxycholate, the absence of elastic effects combined with the overall insensitivity of the remaining time constants makes this possibility appear remote. However, now that tools for doing so are becoming available, quantifying the viscoelastic effects of deoxycholate in addition to the other agonists, inhibitors, and detergents that are applied commonly in the study of ETCs represents an important direction of future inquiry.

\section{Conclusions}

Although the hierarchical origins of the time constants observed are still an issue of debate, the spectral analyses we presented indicate that cells remodel the viscoelastic nature of their environment, and have the potential to communicate through a viscoelastic ECM at higher frequencies. Our spectral analyses revealed that 
human dermal fibroblasts remodeled their environments in such a way as to strengthen some temporal responses

relative to others. These changes resulted in an increase in the energy absorption in the $1 \mathrm{~Hz}$ range, indicating increased damping in the range associated with heart contraction in humans. The cells themselves exhibited damping at time constants sufficiently fast that the ECM would effectively appear elastic, indicating that cells are capable of absorbing and transmitting mechanical signals from one another at these ranges. Results highlight the multifaceted nature of the signals that cells receive, and indicate that the well-known ECM stiffening effects of fibroblasts are enacted over a specific range of viscoelastic time constants. The possible effects of this on cell-cell communication and pathologies of fibrosis warrant continued study.

\section{Acknowledgment}

This work was funded in part by the National Institutes of Health through grant R01HL109505, and by the National Institutes of Health and National Science Foundation through grant U01EB016422.

\section{References}

[1] M. Chiquet, A. S. Renedo, F. Huber, M. Flück, How do fibroblasts translate mechanical signals into changes in extracellular matrix production?, Matrix biology 22 (2003) 73-80.

[2] R. T. Prajapati, M. Eastwood, R. A. Brown, Duration and orientation of mechanical loads determine fibroblast cyto-mechanical activation: Monitored by protease release, Wound repair and regeneration 8 (2000) 238-246.

[3] D. Karamichos, R. Brown, V. Mudera, Collagen stiffness regulates cellular contraction and matrix remodeling gene expression, Journal of Biomedical Materials Research Part A 83 (2007) 887-894.

[4] S.-L. Lee, A. Nekouzadeh, B. Butler, K. M. Pryse, W. B. McConnaughey, A. C. Nathan, W. R. Legant, P. M. Schaefer, R. B. Pless, E. L. Elson, G. Genin, Physically-induced cytoskeleton remodeling of cells in three-dimensional culture, PloS one 7 (2012) e45512.

[5] J. P. Marquez, E. L. Elson, G. M. Genin, Whole cell mechanics of contractile fibroblasts: relations between effective cellular and extracellular matrix moduli, Philosophical Transactions of the Royal Society of London A: Mathematical, Physical and Engineering Sciences 368 (2010) 635-654.

[6] J. P. Marquez, G. M. Genin, G. I. Zahalak, E. L. Elson, Thin bio-artificial tissues in plane stress: the relationship between cell and tissue strain, and an improved constitutive model, Biophysical journal 88 (2005) 765-777.

[7] J. P. Marquez, G. M. Genin, G. I. Zahalak, E. L. Elson, The relationship between cell and tissue strain in three-dimensional bio-artificial tissues, Biophysical journal 88 (2005) 778-789. 
[8] E. Bell, B. Ivarsson, C. Merrill, Production of a tissue-like structure by contraction of collagen lattices by human fibroblasts of different proliferative potential in vitro, Proceedings of the National Academy of Sciences 76 (1979) 1274-1278.

[9] V. H. Barocas, A. G. Moon, R. T. Tranquillo, The fibroblast-populated collagen microsphere assay of cell traction force. part 2: Measurement of the cell traction parameter, Journal of biomechanical engineering 117 (1995) 161-170.

[10] P. Lu, K. Takai, V. M. Weaver, Z. Werb, Extracellular matrix degradation and remodeling in development and disease, Cold Spring Harbor perspectives in biology 3 (2011) a005058.

[11] W. R. Legant, J. S. Miller, B. L. Blakely, D. M. Cohen, G. M. Genin, C. S. Chen, Measurement of mechanical tractions exerted by cells in three-dimensional matrices, Nature methods 7 (2010) 969-971.

[12] A. Nekouzadeh, K. M. Pryse, E. L. Elson, G. M. Genin, Stretch-activated force shedding, force recovery, and cytoskeletal remodeling in contractile fibroblasts, Journal of biomechanics 41 (2008) 2964-2971.

[13] G. I. Zahalak, J. E. Wagenseil, T. Wakatsuki, E. L. Elson, A cell-based constitutive relation for bio-artificial tissues, Biophysical journal 79 (2000) 2369-2381.

[14] T. Wong, J. McGrath, H. Navsaria, The role of fibroblasts in tissue engineering and regeneration, British Journal of Dermatology 156 (2007) 1149-1155.

[15] H. Wang, A. Abhilash, C. S. Chen, R. G. Wells, V. B. Shenoy, Long-range force transmission in fibrous matrices enabled by tension-driven alignment of fibers, Biophysical journal 107 (2014) 2592-2603.

[16] A. Abhilash, B. M. Baker, B. Trappmann, C. S. Chen, V. B. Shenoy, Remodeling of fibrous extracellular matrices by contractile cells: Predictions from discrete fiber network simulations, Biophysical journal 107 (2014) 1829-1840.

[17] R. A. Rowe, K. M. Pryse, C. F. Asnes, E. L. Elson, G. M. Genin, Collective matrix remodeling by isolated cells: Unionizing home improvement do-it-yourselfers, Biophysical journal 108 (2015) 2611-2612.

[18] M. D. Stevenson, A. L. Sieminski, C. M. McLeod, F. J. Byfield, V. H. Barocas, K. J. Gooch, Pericellular conditions regulate extent of cell-mediated compaction of collagen gels, Biophysical journal 99 (2010) 19-28.

[19] W. Wilson, N. Driessen, C. Van Donkelaar, K. Ito, Prediction of collagen orientation in articular cartilage by a collagen remodeling algorithm, Osteoarthritis and Cartilage 14 (2006) 1196-1202.

[20] R. De, A. Zemel, S. A. Safran, Dynamics of cell orientation, Nature Physics 3 (2007) 655-659.

[21] V. H. Barocas, R. T. Tranquillo, An anisotropic biphasic theory of tissue-equivalent mechanics: the interplay among cell traction, fibrillar network deformation, fibril alignment, and cell contact guidance, Journal of biomechanical engineering 119 (1997) 137-145. 
[22] M. Knight, D. Lee, D. Bader, The influence of elaborated pericellular matrix on the deformation of isolated articular chondrocytes cultured in agarose, Biochimica et Biophysica Acta (BBA)-Molecular Cell Research 1405 (1998) 67-77.

[23] B. D. Idowu, M. M. Knight, D. L. Bader, D. A. Lee, Confocal analysis of cytoskeletal organisation within isolated chondrocyte sub-populations cultured in agarose, The Histochemical journal 32 (2000) 165-174.

[24] M. Knight, J. Ross, A. Sherwin, D. Lee, D. Bader, C. Poole, Chondrocyte deformation within mechanically and enzymatically extracted chondrons compressed in agarose, Biochimica et Biophysica Acta (BBA)General Subjects 1526 (2001) 141-146.

[25] T. Wakatsuki, M. S. Kolodney, G. I. Zahalak, E. L. Elson, Cell mechanics studied by a reconstituted model tissue, Biophysical Journal 79 (2000) 2353-2368.

[26] L. Dortmans, A. Sauren, E. Rousseau, Parameter estimation using the quasi-linear viscoelastic model proposed by fung, Journal of biomechanical engineering 106 (1984) 198-203.

[27] E. L. Elson, G. M. Genin, Tissue constructs: platforms for basic research and drug discovery, Interface Focus 6 (2016) 20150095.

[28] S. Kumar, I. Z. Maxwell, A. Heisterkamp, T. R. Polte, T. P. Lele, M. Salanga, E. Mazur, D. E. Ingber, Viscoelastic retraction of single living stress fibers and its impact on cell shape, cytoskeletal organization, and extracellular matrix mechanics, Biophysical journal 90 (2006) 3762-3773.

[29] N. Wang, D. E. Ingber, Control of cytoskeletal mechanics by extracellular matrix, cell shape, and mechanical tension., Biophysical journal 66 (1994) 2181.

[30] B. Babaei, A. Davarian, K. M. Pryse, E. L. Elson, G. M. Genin, Efficient and optimized identification of generalized maxwell viscoelastic relaxation spectra, Journal of the Mechanical Behavior of Biomedical Materials 55 (2015) $32-41$.

[31] G. M. Genin, E. L. Elson, Mechanics of cell-seeded ecm scaffolds, Cell and Matrix Mechanics (2014) 173.

[32] Y.-C. Fung, Biomechanics: mechanical properties of living tissues, Springer Science \& Business Media, 2013.

[33] J. E. Wagenseil, T. Wakatsuki, R. J. Okamoto, G. I. Zahalak, E. L. Elson, One-dimensional viscoelastic behavior of fibroblast populated collagen matrices, Journal of biomechanical engineering 125 (2003) 719725.

[34] R. C. Haut, The influence of specimen length on the tensile failure properties of tendon collagen, Journal of biomechanics 19 (1986) 951-955. 
[35] B. Babaei, S. D. Abramowitch, E. L. Elson, S. Thomopoulos, G. M. Genin, A discrete spectral analysis for determining quasi-linear viscoelastic properties of biological materials, Journal of The Royal Society Interface 12 (2015) 20150707.

[36] T. Wakatsuki, B. Schwab, N. C. Thompson, E. L. Elson, Effects of cytochalasin d and latrunculin b on mechanical properties of cells, Journal of cell science 114 (2001) 1025-1036.

[37] J. P. Marquez, G. M. Genin, K. M. Pryse, E. L. Elson, Cellular and matrix contributions to tissue construct stiffness increase with cellular concentration, Annals of biomedical engineering 34 (2006) 1475-1482.

[38] T. C. Doehring, E. O. Carew, I. Vesely, The effect of strain rate on the viscoelastic response of aortic valve tissue: a direct-fit approach, Annals of Biomedical Engineering 32 (2004) 223-232.

[39] R. De Pascalis, I. D. Abrahams, W. J. Parnell, On nonlinear viscoelastic deformations: a reappraisal of fung's quasi-linear viscoelastic model, Proceedings of the Royal Society of London A: Mathematical, Physical and Engineering Sciences 470 (2014) 20140058.

[40] I. E. Collier, W. Legant, B. Marmer, O. Lubman, S. Saffarian, T. Wakatsuki, E. Elson, G. I. Goldberg, Diffusion of mmps on the surface of collagen fibrils: the mobile cell surface-collagen substratum interface, PLoS One 6 (2011) e24029-e24029.

[41] J. W. Holmes, Z. Laksman, L. Gepstein, Making better scar: Emerging approaches for modifying mechanical and electrical properties following infarction and ablation, Progress in Biophysics and Molecular Biology (2015).

[42] A. D. Rouillard, J. W. Holmes, Mechanical boundary conditions bias fibroblast invasion in a collagen-fibrin wound model, Biophysical journal 106 (2014) 932-943.

[43] G. M. Genin, E. L. Elson, Mechanically guided cell migration: Less of a stretch than ever, Biophysical journal 106 (2014) 776.

[44] G. M. Genin, A. Kent, V. Birman, B. Wopenka, J. D. Pasteris, P. J. Marquez, S. Thomopoulos, Functional grading of mineral and collagen in the attachment of tendon to bone, Biophysical journal 97 (2009) 976-985.

[45] Y. Liu, S. Thomopoulos, C. Chen, V. Birman, M. J. Buehler, G. M. Genin, Modelling the mechanics of partially mineralized collagen fibrils, fibres and tissue, Journal of The Royal Society Interface 11 (2014) 20130835.

[46] Y. Liu, A. G. Schwartz, V. Birman, S. Thomopoulos, G. M. Genin, Stress amplification during development of the tendon-to-bone attachment, Biomechanics and modeling in mechanobiology 13 (2014) 973-983.

[47] S. Thomopoulos, V. Birman, G. M. Genin, Structural interfaces and attachments in biology, New York, NY: Springer Science \& Business Media, 2012.

[48] S. Thomopoulos, G. M. Genin, Tendon and ligament biomechanics, Orthopaedic Biomechanics (2012) 49. 
[49] F. Saadat, V. Birman, S. Thomopoulos, G. M. Genin, Effective elastic properties of a composite containing multiple types of anisotropic ellipsoidal inclusions, with the application to the attachment of tendon to bone, Journal of the Mechanics and Physics of Solids (2015).

[50] R. M. Castile, N. W. Skelley, B. Babaei, R. H. Brophy, S. P. Lake, Microstructural properties and mechanics vary between bundles of the human anterior cruciate ligament during stress-relaxation, Journal of biomechanics (2015).

[51] C. Neu, G. Genin, Handbook of imaging in biological mechanics, Boca Raton, FL: CRC Press, 2014.

[52] M. J. Buehler, G. M. Genin, Integrated multiscale biomaterials experiment and modelling: a perspective, Interface Focus 6 (2016) 20150098.

[53] K. A. Jansen, R. G. Bacabac, I. K. Piechocka, G. H. Koenderink, Cells actively stiffen fibrin networks by generating contractile stress, Biophysical journal 105 (2013) 2240-2251.

[54] C. A. Lemarié, P.-L. Tharaux, S. Lehoux, Extracellular matrix alterations in hypertensive vascular remodeling, Journal of molecular and cellular cardiology 48 (2010) 433-439.

[55] A. Mammoto, T. Mammoto, M. Kanapathipillai, C. W. Yung, E. Jiang, A. Jiang, K. Lofgren, E. P. Gee, D. E. Ingber, Control of lung vascular permeability and endotoxin-induced pulmonary oedema by changes in extracellular matrix mechanics, Nature communications 4 (2013) 1759.

[56] E. Elson, G. Genin, The role of mechanics in actin stress fiber kinetics, Experimental cell research 319 (2013) 2490-2500.

[57] J. Solon, I. Levental, K. Sengupta, P. C. Georges, P. A. Janmey, Fibroblast adaptation and stiffness matching to soft elastic substrates, Biophysical journal 93 (2007) 4453-4461.

[58] M. C. Evans, V. H. Barocas, The modulus of fibroblast-populated collagen gels is not determined by final collagen and cell concentration: experiments and an inclusion-based model, Journal of biomechanical engineering 131 (2009) 101014.

[59] D. M. Knapp, T. T. Tower, R. T. Tranquillo, V. H. Barocas, Estimation of cell traction and migration in an isometric cell traction assay, AIChE journal 45 (1999) 2628-2640.

[60] L. Gyoneva, C. B. Hovell, R. J. Pewowaruk, K. D. Dorfman, Y. Segal, V. H. Barocas, Cell-matrix interaction during strain-dependent remodelling of simulated collagen networks, Interface Focus 6 (2016) 20150069.

[61] B. M. Baker, B. Trappmann, W. Y. Wang, M. S. Sakar, I. L. Kim, V. B. Shenoy, J. A. Burdick, C. S. Chen, Cell-mediated fibre recruitment drives extracellular matrix mechanosensing in engineered fibrillar microenvironments, Nature materials (2015). 
[62] A. Nair, B. M. Baker, B. Trappmann, C. S. Chen, V. B. Shenoy, Remodeling of fibrous extracellular matrices by contractile cells: Predictions from discrete fiber network simulations, arXiv preprint arXiv:1409.6216 (2014).

[63] V. S. Shenoy, A free energy based approach to model durotaxis and extracellular stiffness-dependent contraction and polarization of cells, Interface Focus 0 (2015) 0-1.

[64] R. L. Trelstad, K. Hayashi, J. Gross, Collagen fibrillogenesis: intermediate aggregates and suprafibrillar order, Proceedings of the National Academy of Sciences 73 (1976) 4027-4031.

[65] H. Gupta, J. Seto, S. Krauss, P. Boesecke, H. Screen, In situ multi-level analysis of viscoelastic deformation mechanisms in tendon collagen, Journal of structural biology 169 (2010) 183-191.

[66] H. Screen, J. Seto, S. Krauss, P. Boesecke, H. Gupta, Extrafibrillar diffusion and intrafibrillar swelling at the nanoscale are associated with stress relaxation in the soft collagenous matrix tissue of tendons, Soft Matter 7 (2011) 11243-11251.

[67] B. Xu, H. Li, Y. Zhang, Understanding the viscoelastic behavior of collagen matrices through relaxation time distribution spectrum, Biomatter 3 (2013) e24651.

[68] A. Gautieri, S. Vesentini, A. Redaelli, M. J. Buehler, Viscoelastic properties of model segments of collagen molecules, Matrix Biology 31 (2012) 141-149.

[69] A. Gautieri, S. Vesentini, F. M. Montevecchi, A. Redaelli, Mechanical properties of physiological and pathological models of collagen peptides investigated via steered molecular dynamics simulations, Journal of biomechanics 41 (2008) 3073-3077.

[70] M. Galderisi, Diastolic dysfunction and diabetic cardiomyopathy: evaluation by doppler echocardiography, Journal of the American College of Cardiology 48 (2006) 1548-1551.

[71] X. Zhou, L. Ma, J. Habibi, A. Whaley-Connell, M. R. Hayden, R. D. Tilmon, A. N. Brown, J.-a. Kim, V. G. DeMarco, J. R. Sowers, Nebivolol improves diastolic dysfunction and myocardial remodeling through reductions in oxidative stress in the zucker obese rat, Hypertension 55 (2010) 880-888.

[72] K. Ragaert, F. De Somer, P. Somers, I. De Baere, L. Cardon, J. Degrieck, Flexural mechanical properties of porcine aortic heart valve leaflets, journal of the mechanical behavior of biomedical materials 13 (2012) 78-84.

[73] M. Kalejs, P. Stradins, R. Lacis, I. Ozolanta, J. Pavars, V. Kasyanov, St jude epic heart valve bioprostheses versus native human and porcine aortic valves-comparison of mechanical properties, Interactive cardiovascular and thoracic surgery 8 (2009) 553-556.

[74] S. A. O'Leary, B. J. Doyle, T. M. McGloughlin, The impact of long term freezing on the mechanical properties of porcine aortic tissue, Journal of the mechanical behavior of biomedical materials 37 (2014) 165-173. 
[75] P. K. Wong, W. Tan, C.-M. Ho, Cell relaxation after electrodeformation: effect of latrunculin a on cytoskeletal actin, Journal of biomechanics 38 (2005) 529-535.

[76] X. Trepat, L. Deng, S. S. An, D. Navajas, D. J. Tschumperlin, W. T. Gerthoffer, J. P. Butler, J. J. Fredberg, Universal physical responses to stretch in the living cell, Nature 447 (2007) 592-595.

[77] K. M. Pryse, A. Nekouzadeh, G. M. Genin, E. L. Elson, G. I. Zahalak, Incremental mechanics of collagen gels: new experiments and a new viscoelastic model, Annals of biomedical engineering 31 (2003) 1287-1296.

[78] J. Liao, E. M. Joyce, M. S. Sacks, Effects of decellularization on the mechanical and structural properties of the porcine aortic valve leaflet, Biomaterials 29 (2008) 1065-1074.

[79] N. Gundiah, K. Kam, P. B. Matthews, J. Guccione, H. A. Dwyer, D. Saloner, T. A. Chuter, T. S. Guy, M. B. Ratcliffe, E. E. Tseng, Asymmetric mechanical properties of porcine aortic sinuses, The Annals of thoracic surgery 85 (2008) 1631-1638.

[80] Z. Qin, A. Gautieri, A. K. Nair, H. Inbar, M. J. Buehler, Thickness of hydroxyapatite nanocrystal controls mechanical properties of the collagen-hydroxyapatite interface, Langmuir 28 (2012) 1982-1992.

[81] M. A. Nicosia, J. S. Kasalko, R. P. Cochran, D. R. Einstein, K. S. Kunzelman, Biaxial mechanical properties of porcine ascending aortic wall tissue., The Journal of heart valve disease 11 (2002) 680-6.

[82] S. Pittaccio, F. Migliavacca, V. Hjordtal, M. Smerup, E. Fründ, T. Villa, E. Morre-Pedersen, M. De Leval, Aortic tissue properties in porcine models: a comparison of ex vivo mechanical test results after simulated aortic arch reconstructions, Journal of Applied Biomaterials \& Biomechanics 3 (2005) 147-156.

[83] N. Dong, X. Ye, Z. Sun, J. Shi, Y. Qiu, J. Chen, [experimental study on mechanical properties of decellularized porcine aortic valve and effects of precoating methods of biological scaffold on histocompatibility]., Zhonghua wai ke za zhi [Chinese journal of surgery] 45 (2007) 1128-1131.

[84] F. H. Silver, D. L. Christiansen, P. B. Snowhill, Y. Chen, Transition from viscous to elastic-based dependency of mechanical properties of self-assembled type i collagen fibers, Journal of applied polymer science 79 (2001) 134-142.

[85] Z. L. Shen, H. Kahn, R. Ballarini, S. J. Eppell, Viscoelastic properties of isolated collagen fibrils, Biophysical journal 100 (2011) 3008-3015.

[86] G. E. Chapman, S. S. Danyluk, K. McLauchlan, A model for collagen hydration, Proceedings of the Royal Society of London B: Biological Sciences 178 (1971) 465-476.

[87] E. Wachtel, A. Maroudas, The effects of ph and ionic strength on intrafibrillar hydration in articular cartilage, Biochimica et Biophysica Acta (BBA)-General Subjects 1381 (1998) 37-48.

[88] I. G. Mogilner, G. Ruderman, J. R. Grigera, Collagen stability, hydration and native state, Journal of molecular Graphics and Modelling 21 (2002) 209-213. 
[89] D. P. McDaniel, G. A. Shaw, J. T. Elliott, K. Bhadriraju, C. Meuse, K.-H. Chung, A. L. Plant, The stiffness of collagen fibrils influences vascular smooth muscle cell phenotype, Biophysical journal 92 (2007) 1759-1769.

[90] A. Gautieri, S. Vesentini, A. Redaelli, M. J. Buehler, Hierarchical structure and nanomechanics of collagen microfibrils from the atomistic scale up, Nano letters 11 (2011) 757-766.

[91] Z. Feng, M. Yamato, T. Akutsu, T. Nakamura, T. Okano, M. Umezu, Investigation on the mechanical properties of contracted collagen gels as a scaffold for tissue engineering, Artificial organs 27 (2003) 84-91.

[92] J. P. Marquez, G. M. Genin, E. L. Elson, On the application of strain factors for approximation of the contribution of anisotropic cells to the mechanics of a tissue construct, Journal of biomechanics 39 (2006) 2145-2151. 


\section{Figure legends}

Figure 1. Development of engineered tissue constructs (ETCs) over 72 hours, including variations of their cross-sectional area, of the number of cells within them, and of the number of cells per unit volume (cell concentration). (a) The cross-sectional areas of the ETCs reduced to a minimum of $\sim 5 \times 10^{-7} \mathrm{~m}^{2}$ over approximately 36 hours as the cells remodeled the collagen. (b) The cell population varied during this compaction, with the number of cells within each (initially $0.5 \mathrm{ml}$ ) ETC rising from $250 \times 10^{3}$ over the first 24 hours of observation, then decreasing to approximately $190 \times 10^{3}$ over 72 hours. (c) Throughout incubation, the cell concentration rose steadily. All error bars represent standard deviation.

Figure 2. Stress relaxation curves showing the variation of stress over time in engineered tissue constructs (ETCs) that were held isometrically at $10 \%$ stretch immediately following a linear ramp to $10 \%$ stretch over $0.5 \mathrm{~s}$. The isometric force required to sustain ETCs at $10 \%$ stretch relaxed viscoelastically. Left column (a, $\mathrm{c}, \mathrm{e})$ : ETCs tested in nutritional medium; right column (b, d, f): ETCs tested in nutritional medium plus deoxycholate to lyse cells. Three time points were considered: 24 hours (a, b), 48 hours (c, d), and 72 hours (e, f). The data presented are representative; replicate data are presented in the supplementary document, Figures S1 (24 hours), S3 (48 hours), and S5 (72 hours).

Figure 3. Variations of the peak stress (immediately following ramp loading, solid circles) and minimum stress (reached after $3600 \mathrm{~s}$ of relaxation, hollow circles) attained during stress relaxation tests on engineered tissue constructs (ETCs) that remodeled for 24, 48, or 72 hours prior to testing. (a) In ETCs tested in nutritional medium only, a statistically significant increase was observed in peak stress between 48 and 72 hours. (b) In ETCs tested following treatment with deoxycholate, a significant increase was observed in the minimum stress between 24 and 48 hours. Error bars: standard deviation. Criterion for significance: $p<0.05$ in Student's T-test.

Figure 4. Viscoelastic relaxation spectra of ETCs tested in nutritional medium (left column, panels a, c, and e) or nutritional medium plus deoxycholate to lyse cells (right column, panels b, d, and f). Cells and ECM displayed distinguishable contributions to the ETC viscoelasticity, with the latter changing over the course of ECM remodeling. Three time points were considered: 24 hours (a, b), 48 hours (c, d), and 72 hours (e, f). The time constants of the ETCs were similar at the three different tissue ages. The exception was that during 48-72 hours of the remodeling the two time constants between 1 and $10 \mathrm{~s}$ merged into a single time constant at about $2 \mathrm{~s}$. In the deoxycholate treated ETCs the $0.2 \mathrm{~s}$ and $30 \mathrm{~s}$ peaks were absent. Each panel corresponds to a single, representative specimen. Replicate spectra are presented in the supplementary document, Figures S2 (24 hours), S4 (48 hours), and S6 (72 hours).

Figure 5. Confocal reflectance microscopy images of collagen fibers (green) superimposed upon images of cells (red) in engineered tissue constructs. Although little effect was evident in the viscoelastic time constants, remodeling corresponded to a substantial change in ECM morphology. (a) A random collagen distribution was evident at 24 hours. (b) The collagen fibers were more organized and began to exhibit a preferred orientation at 48 hours. (c) A very compact pattern of collagen fibers was observed at 72 hours. Red: cell membranes; green: signal from confocal reflectance. Scale bar, $50 \mu \mathrm{m}$. 
Figure 6. A confocal reflectance microscopy image of collagen fibers (green) superimposed upon images of cells (red) in engineered tissue constructs. During the remodeling, the cells established a connective network, with some clusters of adjacent cells forming ring-like structures. The network appeared to link and organize individual cells in the ECM. Mechanical signals sent to amongst cells over a timescale faster than the fastest time constant in these collagen bundles are not attenuated by the bundles. Scale bar, $50 \mu \mathrm{m}$. 


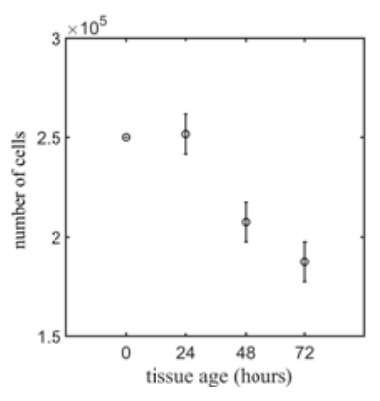

(a)

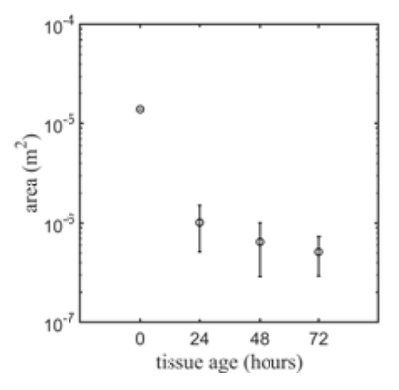

(b)

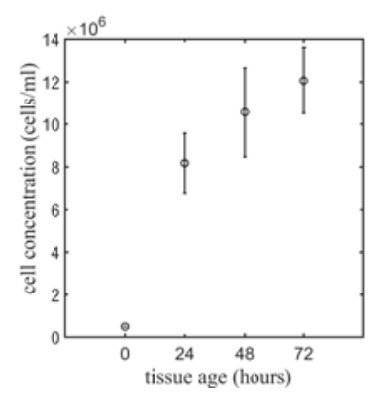

(c)

Figure 1: 


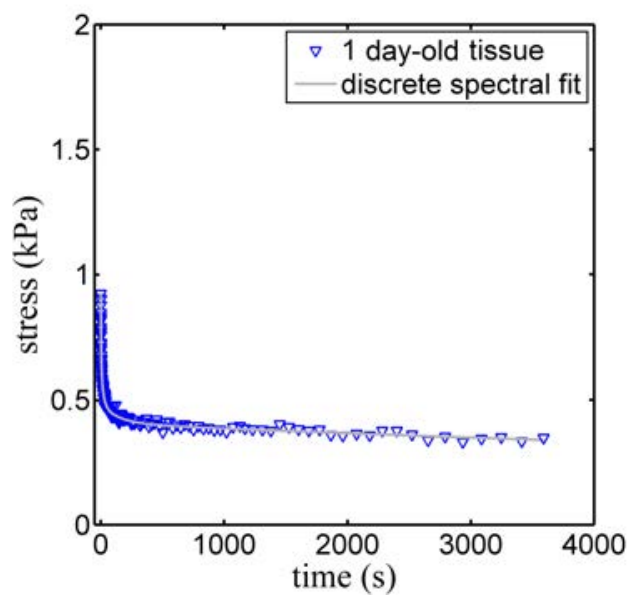

(a)

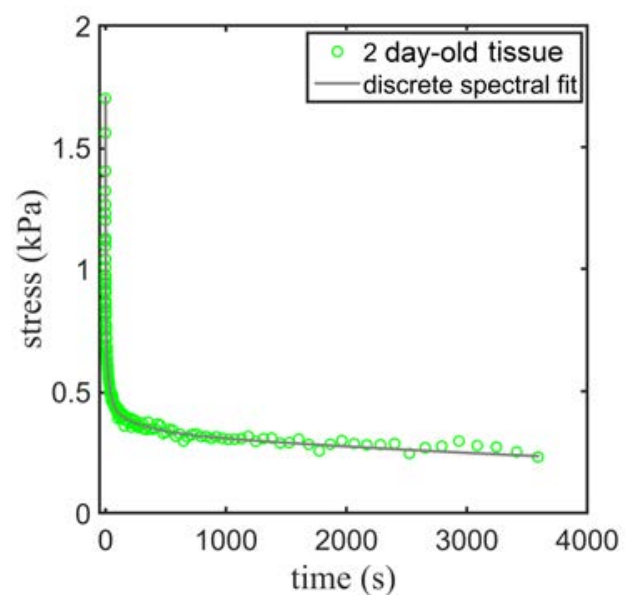

(c)

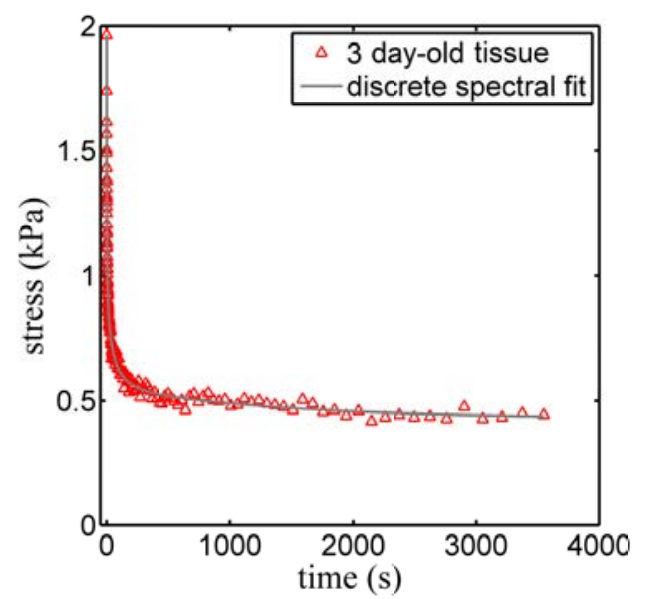

(e)

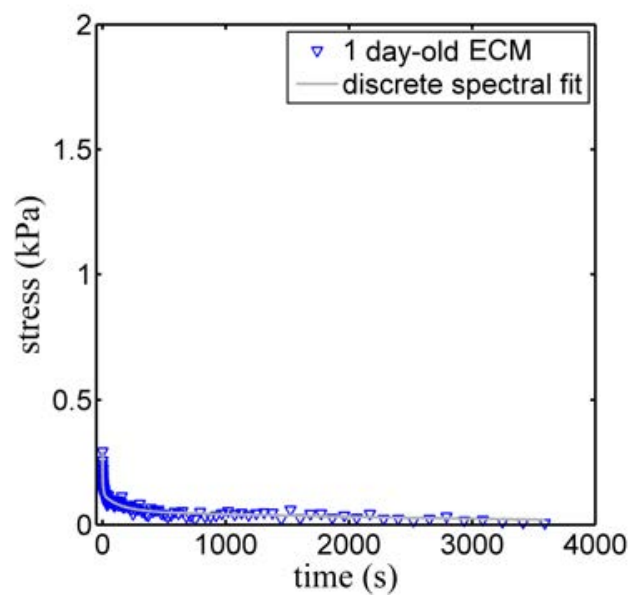

(b)

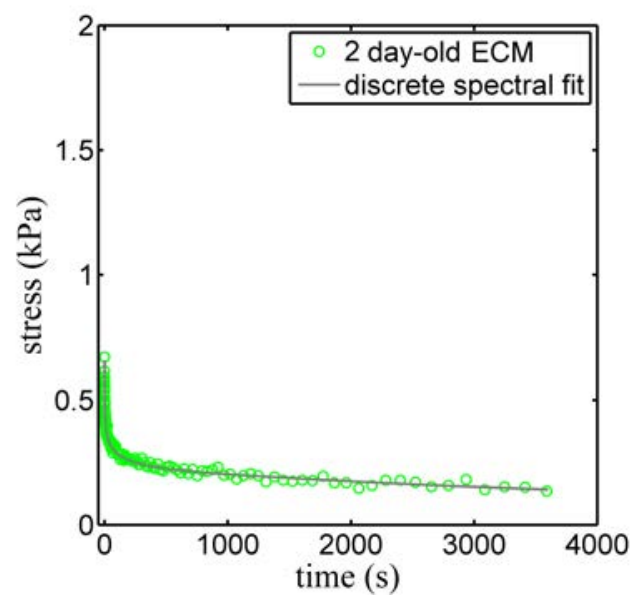

(d)

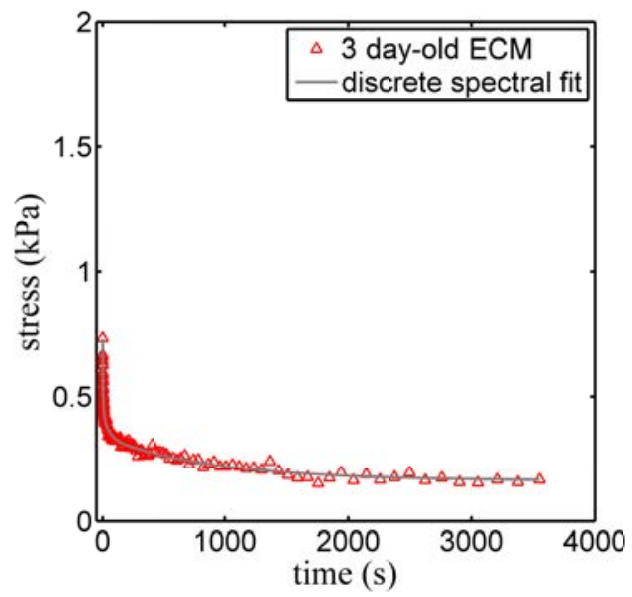

(f)

Figure 2: 


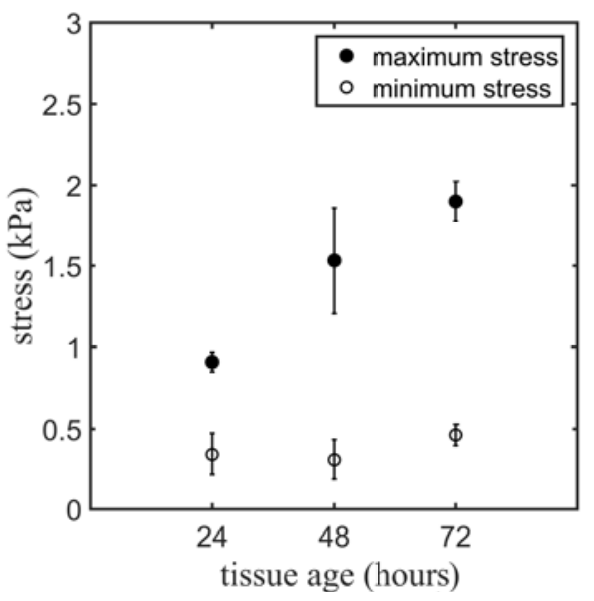

(a)

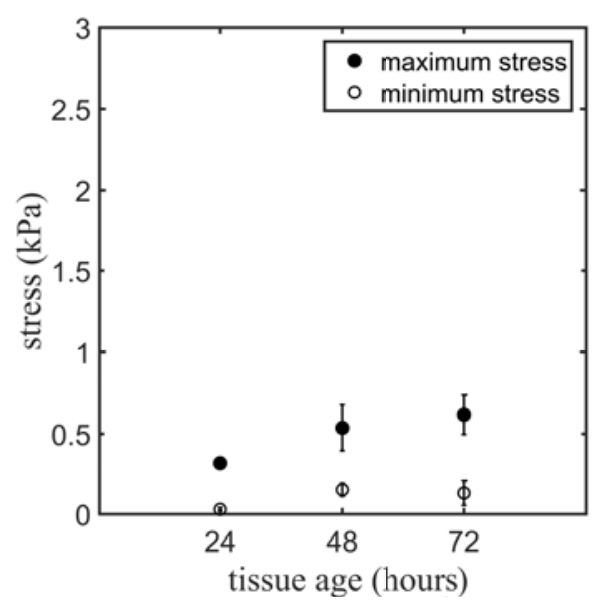

(b)

Figure 3: 


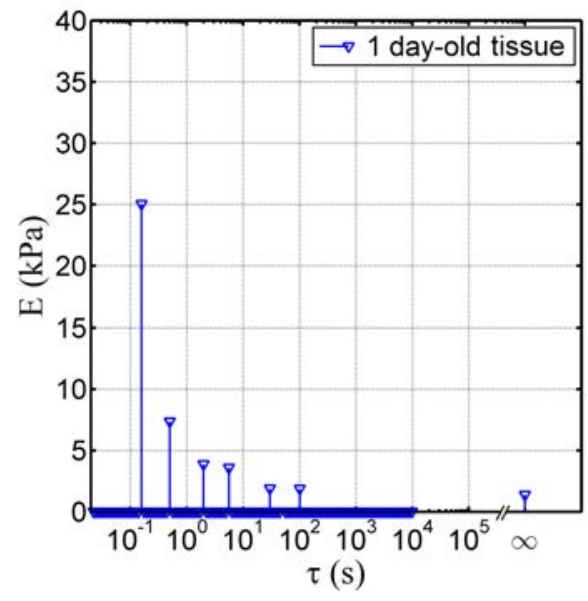

(a)

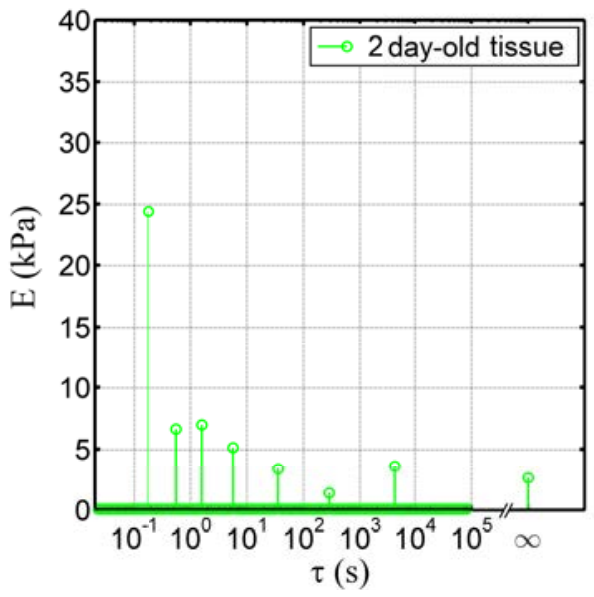

(c)

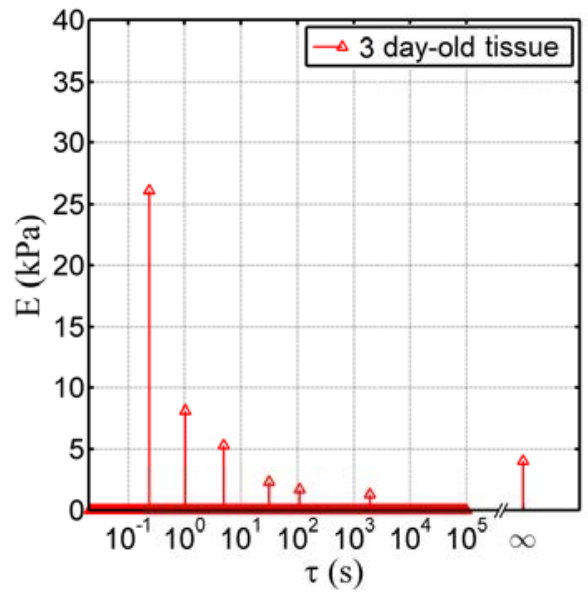

(e)

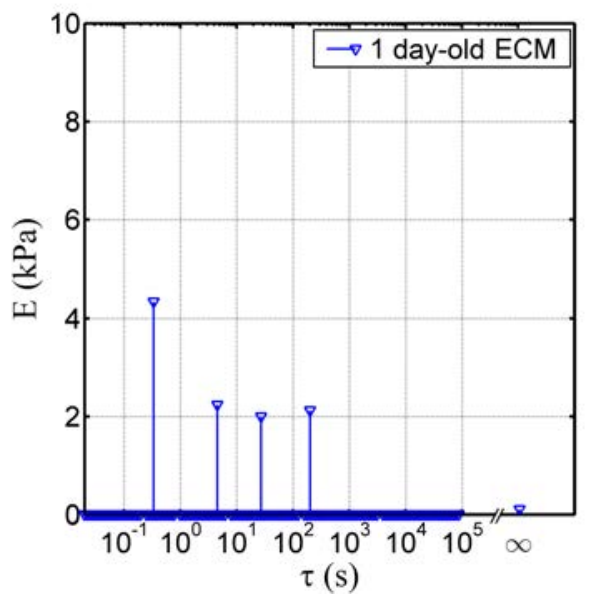

(b)

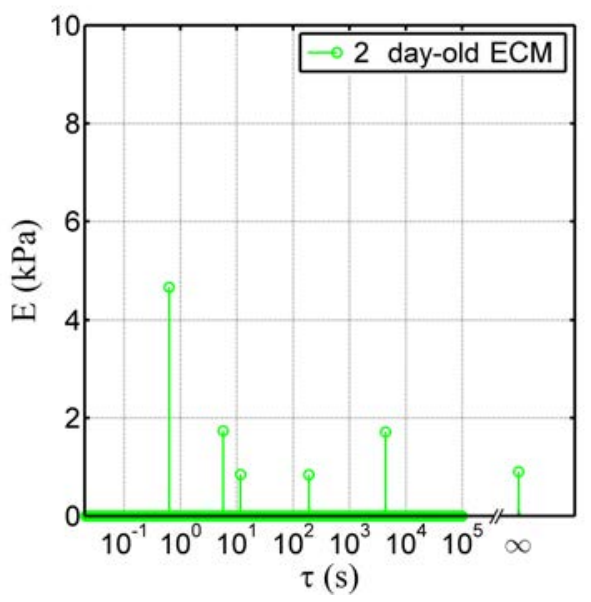

(d)

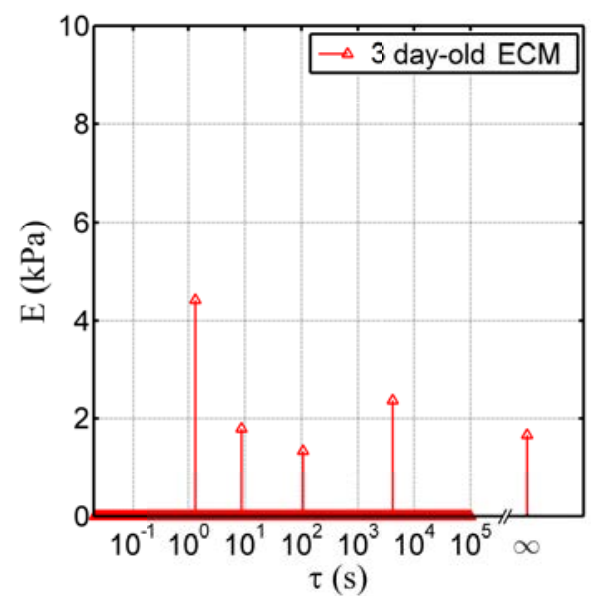

(f)

Figure 4: 


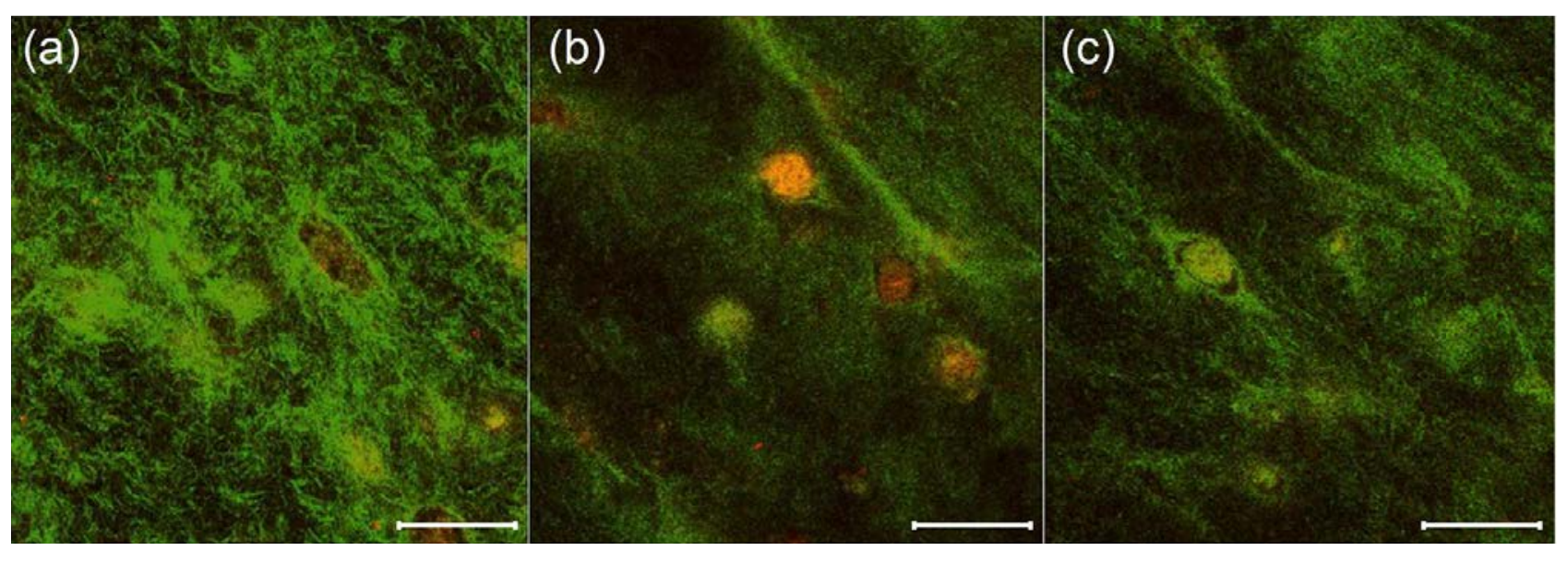

Figure 5: 


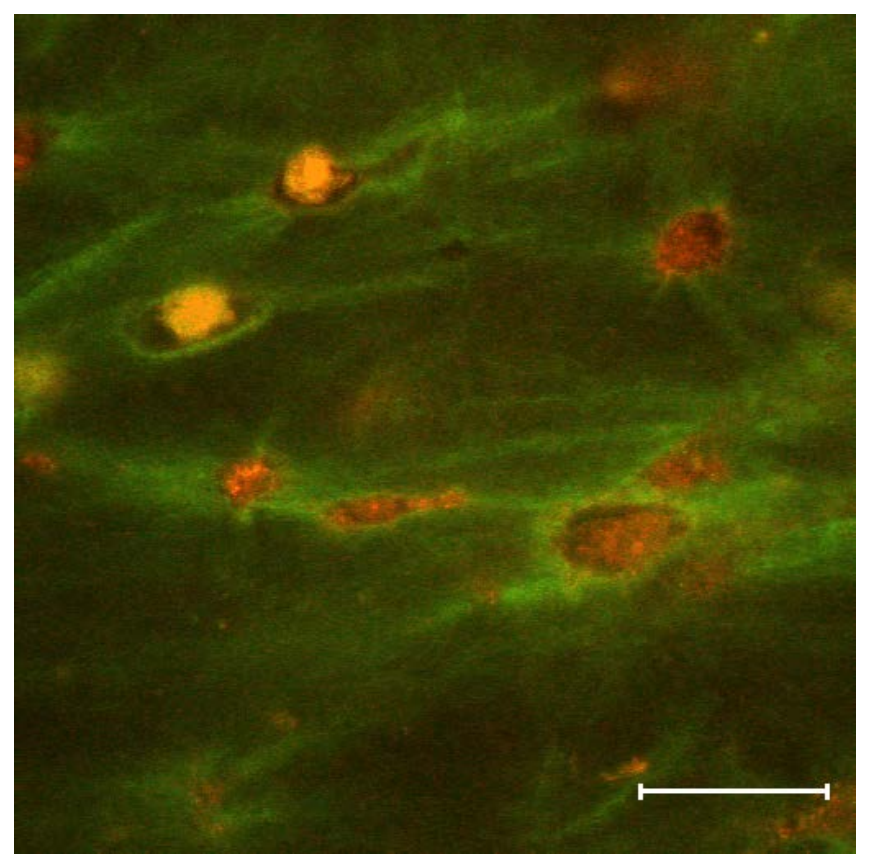

Figure 6: 


\section{${ }^{*}$ Graphical Abstract}
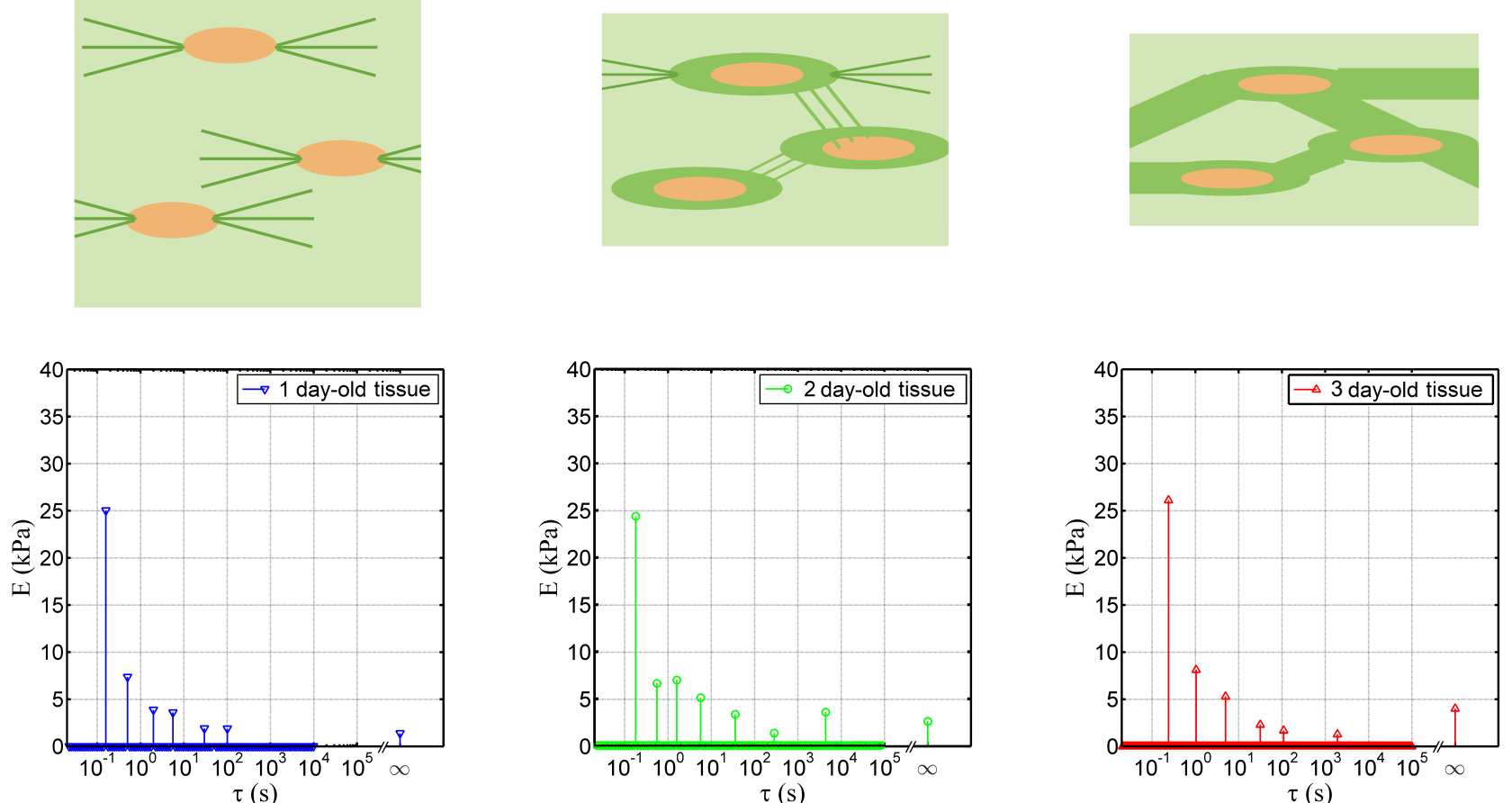